\title{
Establishment and Application of Evaluation Model of College Students' Entrepreneurial Ability in Perspective of Youth League
}

\author{
Zhang Peng ${ }^{1}$, Li Meng ${ }^{1}$,Wang Bin ${ }^{2 *}$ \\ ${ }^{1}$ College of physical education, Beihua University, China \\ ${ }^{2}$ School of Forestry and Bio-technology, Zhejiang A\&F University, China \\ *Corresponding author
}

Keywords: Youth League, College students, Entrepreneurial ability evaluation.

\begin{abstract}
Based on the reality of application-oriented undergraduate universities, the evaluation model of college students' entrepreneurial ability is established applying the matter-element and extension set theories in perspective of the youth league. The empirical study of entrepreneurial ability evaluation is conducted, taking the students in the Beihua university student pioneering zone as an example. Results showed that the evaluation results are consistent with the actual situation of students' entrepreneurial ability, indicating that the evaluation model of multidimensional extension matter - element entrepreneurial ability is feasible. It was helpful to college students to correctly understand themselves, and grasp the entrepreneurial opportunities.
\end{abstract}

\section{Introduction}

Under the background of mass innovation and entrepreneurship, the innovation and entrepreneurship education of college students caused the attention of the whole society once again.in perspective of youth league, how to improve the entrepreneurial ability of college students is an important topic to steadily promote "the implement opinion on college youth league promoting college students' entrepreneurship" in the new situation. And evaluating the entrepreneurial ability of college students is one of the important ways to improve their entrepreneurial abilities ${ }^{[1]}$.

However, there are few research results on the evaluation of college students' entrepreneurial ability. And there are not yet an effective analysis method to accurately measure the entrepreneurial ability of college students ${ }^{[2]}$. Extension theory was founded in 1983. it provided a methodological system to understand the real world and to solve the complex problems in the real world in a new perspective $^{[3]}$. Based on the matter-element theory and extension set theory of extenics, this paper proposed a multidimensional extension matter-element model for the evaluation of college students' entrepreneurial ability. The model can not only formalized describe the various factors that affect the entrepreneurial ability of college students, but also can give the qualitative and quantitative evaluation of college students 'entrepreneurial ability accurately, thus fully reflecting the advantages and disadvantages of college students' entrepreneurship. At the end of this paper, the feasibility and validity of the model were illustrated by case analysis. So it has strong practical value.

\section{Multidimensional Extension Matter-element Model for Evaluation of College Students' Entrepreneurship}

\subsection{Definition of Matter-element}

As we all know, everything has its own characteristics. It is a sign of being different from other things. If the name of a thing is $\mathrm{N}$, one of its characteristic is $\mathrm{c}$, the corresponding value of the characteristic $\mathrm{c}$ is $\mathrm{u}$. The ordered triples 
If the thing $\mathrm{N}$ is described by the $\mathrm{h}$ main features $\mathrm{c}_{1}, \mathrm{c}_{2}, \ldots \mathrm{c}_{\mathrm{h}}$, and the corresponding values $\mathrm{v}_{1}$, $\mathrm{v}_{2}, \ldots \mathrm{v}_{\mathrm{h}}$, then the main feature matter-element matrix of the thing is as follows:

$$
R=\left[\begin{array}{l}
N, c_{1}, v_{1} \\
N, c_{2}, v_{2} \\
\cdots \cdots \cdots \cdots . . . \\
N, c_{h}, v_{h}
\end{array}\right]=\left[\begin{array}{l}
R_{1} \\
R_{2} \\
\cdots \\
R_{h}
\end{array}\right]
$$

\subsection{Classical domain matter-element model and node domain matter-element model}

\subsubsection{Construction of evaluation index system for college students' entrepreneurship}

Therefore, the entrepreneurial abilities of college students are divided into two categories in this study: college students' entrepreneurial knowledge and college students' entrepreneurial skills ${ }^{[4]}$. These are the primary indicators to evaluate the college students' entrepreneurial ability. Then, based on the related research results at home and abroad ${ }^{[5]}$, and according to the comprehensive, concise, guiding, independence, and operability principles, combined with experts' opinions, the college students' entrepreneurial knowledge and entrepreneurial skills index were constructed. The former includes: professional knowledge $X_{1}$, management knowledge $X_{2}$, legal knowledge $X_{3}$, total three secondary indicators. The latter includes: innovation ability $\mathrm{X}_{4}$, learning ability $\mathrm{X}_{5}$, organizational ability $\mathrm{X}_{6}$, communication ability $\mathrm{X}_{7}$, execution ability $\mathrm{X}_{8}$, public relations ability $\mathrm{X}_{9}$, decision ability $\mathrm{X}_{10}$, psychological control ability $\mathrm{X}_{11}$, total eight secondary indicators. That is, the evaluation index system on the entrepreneurial ability contains 2 primary indicators and 11 secondary indicators.

\subsubsection{Model building}

There are $\mathrm{m}$ index that indicate the entrepreneurial ability of college students $\left(\mathrm{X}_{1}, \mathrm{X}_{2}, \cdots, \mathrm{X}_{\mathrm{m}}\right.$, from the above we can see $\mathrm{m}=11$ ), college students' entrepreneurial ability is divided into $\mathrm{n}$ grades. The index and the corresponding value of the entrepreneurial ability of college students are expressed by the following matter-element model (called "classical domain matter-element matrix"):

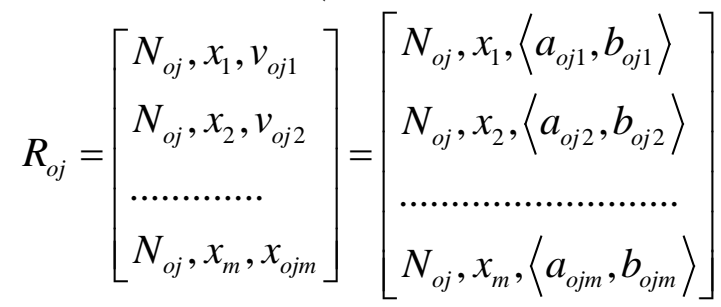

where $N_{o j}$ indicates that the entrepreneurial ability of the college students is at the $j$-level; $R_{o j}$ indicates the matter-element model when the entrepreneurial ability of the college students is at the $\mathrm{j}$ level; $\mathrm{V}_{0 \mathrm{jk}}=\left\langle a_{o j k}, b_{o j k}\right\rangle$ indicates the value range of the index $\mathrm{x}_{\mathrm{k}}$ (which is in the $\mathrm{j}$-level ) of the number $\mathrm{k}$ factor of entrepreneurial ability, $\mathrm{j}=1,2, \ldots, \mathrm{n} ; \mathrm{k}=1,2, \ldots, \mathrm{m}$.

From the classical domain matter- element matrix, we can see that the "node domain matterelement matrix" is the matter-element model which factors that indicated the college student's entrepreneurial ability are within the allowable range:

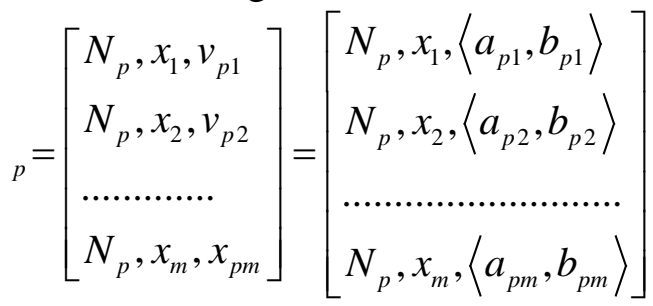


where $R_{p}$ is the node domain of the matter-element model to evaluate the students' entrepreneurial ability; $\mathrm{N}_{\mathrm{p}}$ is the whole grade of the college students' entrepreneurial ability; $\mathrm{V}_{\mathrm{pk}}=$ $\left\langle a_{p k}, b_{p k}\right\rangle$ is the allowable value range of the index $\mathrm{x}_{\mathrm{k}}$ in $\mathrm{N}_{\mathrm{p}} ; \mathrm{V}_{\mathrm{ojk}} \subset \mathrm{V}_{\mathrm{pk}}, \mathrm{J}=1,2, \cdots \mathrm{n} ; \mathrm{k}=1,2, \cdots, \mathrm{m}$.

\subsection{Establishment of matter-element model to evaluate the college students' entrepreneurial ability}

The index $\mathrm{X}_{1}, \mathrm{X}_{2}, \cdots, \mathrm{X}_{\mathrm{m}}$ of the students' entrepreneurial ability (to be evaluated) are evaluated. The values $\mathrm{V}_{1}, \mathrm{~V}_{2}, \cdots, \mathrm{Vm}$ are indicated by the following matter-element matrix:

$$
R=\left[\begin{array}{l}
N, x_{1}, v_{1} \\
N, x_{2}, v_{2} \\
\cdots \cdots \cdots \cdots . . . \\
N, x_{m}, x_{m}
\end{array}\right]
$$

where $\mathrm{N}$ is the entrepreneurial ability to be evaluated; $\mathrm{v}_{\mathrm{k}}$ is the evaluation value of the index $\mathrm{x}_{\mathrm{k}}$ of the $\mathrm{k}$ factor of the entrepreneurial ability to be evaluated $(\mathrm{k}=1,2, \ldots, \mathrm{m})$.

\section{Extension evaluation method for college students' entrepreneurship}

How to evaluate the grade of the entrepreneurial ability of college students after establishing the multidimensional extension evaluation matter-element model for college students' entrepreneurial ability? To solve this problem, we need to calculate the "proximity" of the entity element matrix (formula (5)) and the classical domain matter element matrix (formula (3)). Here, we use the correlation function in the extension set to calculate the "proximity".

\subsection{Definition of proximity}

Let

$$
\begin{aligned}
& p\left(v_{k}, V_{o j k}\right)=\left|v_{k}-\frac{a_{o j k}+b_{o j k}}{2}\right|-\frac{1}{2}\left(b_{o j k}-a_{o j k}\right) \\
& (k=1,2, \ldots, m ; j=1,2, \ldots, n) \\
& p\left(v_{k}, V_{p k}\right)=\left|v_{k}-\frac{a_{p k}+b_{p k}}{2}\right|-\frac{1}{2}\left(b_{p k}-a_{p k}\right) \\
& (k=1,2, \ldots, m ; j=1,2, \ldots, n)
\end{aligned}
$$

indicate the proximity between the $v_{k}$ (evaluation value) and the interval $V_{o j k}, V_{p k}$ respectively. For example, $\mathrm{P}\left(\mathrm{v}_{\mathrm{k}}, \mathrm{V}_{\mathrm{pk}}\right) \geqq 0$, indicating that $\mathrm{v}_{\mathrm{k}}$ is not within range $\mathrm{V}_{\mathrm{pk}}, \mathrm{p}\left(\mathrm{v}_{\mathrm{k}}, \mathrm{V}_{\mathrm{pk}}\right) \leqq 0$ means vk is within range $V_{p k}$, and different negative values indicate $v_{k}$ is in different positions within range $V_{p k}$.

\subsection{Establishment of correlation}

Let

$$
\begin{aligned}
& K_{j}\left(v_{k}\right)=\frac{p\left(v_{k}, V_{o j k}\right)}{p\left(v_{k}, V_{p k}\right)-p\left(v_{k}, V_{o j k}\right)} \\
& j=1,2, \ldots, n ; l=1,2, \ldots, m
\end{aligned}
$$

indicates the correlation of the index $\mathrm{xk}$ of the $\mathrm{k}$ factor of the entrepreneurial ability to be evaluated in j-level. $-\infty<\mathrm{K}_{\mathrm{j}}\left(\mathrm{v}_{\mathrm{k}}\right)<+\infty \cdot \mathrm{K}_{\mathrm{j}}\left(\mathrm{v}_{\mathrm{k}}\right) \geq 0$ indicates that vk belongs to $\mathrm{V}_{\mathrm{ojk}}$, the bigger of $\mathrm{K}_{\mathrm{j}}\left(\mathrm{V}_{\mathrm{k}}\right)$ indicates vk has more attributes with $\mathrm{V}_{\mathrm{ojk}}, \mathrm{K}_{\mathrm{j}}\left(\mathrm{V}_{\mathrm{k}}\right) \leq 0$ indicates $\mathrm{V}_{\mathrm{k}}$ doesn't belong to $\mathrm{V}_{\mathrm{ojk}}$, the smaller of $K_{j}\left(V_{k}\right)$ indicates $v_{k}$ is farther away form range $V_{o j k}$. 


\subsection{Determination of the level of the college students' entrepreneurial ability}

From the formula (8) we can calculate the correlation matrix of the evaluation index and the level of the college students' entrepreneurial ability

$$
K=\left[K_{J}\left(v_{k}\right)_{m \times n}\right]
$$

According to the correlation matrix, calculate

$$
\max _{1 \leq j \leq n} K_{j}\left(v_{k}\right)=K_{i_{0}}\left(v_{k}\right)=K^{*}\left(v_{k}\right)_{\mathrm{k}=1,2, \ldots, \mathrm{m}}
$$

Then $\mathrm{K}_{\mathrm{ip}}\left(\mathrm{v}_{\mathrm{k}}\right)$ Indicates the index $\mathrm{x}_{\mathrm{k}}$ of the $\mathrm{k}$ factor of the entrepreneurial ability is in j-level, and it can be used to evaluate the entrepreneurial ability.

If $w_{k}\left(\sum_{k=1}^{m} w_{k}=1\right)$ is ability to be evaluated and the entrepreneurial ability in the j-level is

$$
K_{j}(R)=\sum_{k=1}^{m} w_{k} K_{j}\left(v_{k}\right)
$$

This is a comprehensive consideration on the fact that the index of the college students' entrepreneurial ability evaluation factors has different infected degree on the entrepreneurial ability. So it has a strong scientific and feasibility.

Calculate

$$
K_{j_{0}}(R)=\max _{1 \leq j \leq n} K_{j}(R)
$$

Then the grade of the entrepreneurial ability is on $\mathrm{j}_{0}$ level.

\section{Empirical study}

In this study, three college students (student A1, student A2 and student A3) who were engaged in entrepreneurship were selected from the beihua university's pioneering zone. The entrepreneurial abilities of the three students were evaluated by the above method.

\section{1the quantitative assessment group of the index system has been set up}

The group has 2 representatives of the classmates, 1 counselor, 2 persons in charge of enterprises, 2 employment and Entrepreneurship teachers, 4 experts in relative fields, a total of 11 people.

\subsection{Calculation of the correlation matrix}

According to the formula (8), the correlation matrix of the evaluation index and the level of the entrepreneurial ability of student A1 can be calculated.

\subsection{Calculation of the correlation of entrepreneurial ability}

From (11) we can see that the correlation of the entrepreneurial ability of student A1 and the jlevel entrepreneurial ability is

$$
K_{j}(R)=\sum_{k=1}^{11} w_{k} K_{j}\left(v_{k}\right)(j=1,2,3,4,5)
$$

The weight coefficient of the index of the entrepreneurial ability and the data in the correlation matrix were brought into the above formula, it can be obtained by calculation

That is,

$$
K_{j}(R)=\sum_{k=1}^{11} w_{k} K_{j}\left(v_{k}\right)=(-0.6367-0.5150-0.2759-0.1261-0.1562)
$$

$$
K_{1}(R)=-0.6367, K_{2}(R)=-0.5150, K_{3}(R)=-0.2759, K_{4}(R)=-0.1261, K_{5}(R)=-0.1562
$$
So, 


$$
K_{j_{0}}(R)=\max _{1 \leq j \leq 5} K_{j}(R)=K_{4}(R)=0.1261
$$

This showed that student A1's entrepreneurial ability level was the fourth. that was, strong entrepreneurial ability.

Similarly, we evaluated the entrepreneurial ability of students A2 and students A3 using the above methods (the same process). The results are that student A2's and A3's entrepreneurial ability level was the second and third respectively. that was, student A2 and A3 had poor and general entrepreneurial ability respectively.

This was consistent with the actual situation of the three college students. in the first year of the university, student A1 began to participate in entrepreneurial activities, founded the university campus DM "fashion newspaper". in his third grade he founded his own business - Jilin Feng Hua campus culture company. He has experienced difficulties during the company development, but he solved the problems actively and timely. At present, the company's overall sales revenue grew steadily and the momentum of development was good. Students A2 had high passion in the start. During the entrepreneurial process he encountered a lot of problems. However, he did not want to overcome them, then he had given up his business. In the entrepreneurial process, student A3 was not good at communicating with the team members, coupled with the lack of decisive business. His enterprise was in a difficult situation.

\section{Conclusion}

The paper take the college students' entrepreneurial activities carried out by youth league as the starting point. Based on the theory of matter-element theory and extension set theory in the extenics, the multidimensional extension matter-element model of college students' entrepreneurial ability evaluation has been built. This model comprehensively considers the various factors of college students 'entrepreneurial ability, can objectively and accurately evaluate the entrepreneurial ability of college students. It provides a new way for the evaluation of college students' entrepreneurial ability, and has a certain application prospects.

\section{Acknowledgements}

This research was financially supported by National school youth league research project of the Central School Department of China Communist Youth League (2017LX043) and Research project of education and teaching reform of Beihua University in 2017.

\section{References}

[1] Chinese college student employment report in 2016. China Education Online [EB/OL]. (20166-12) [2016-8-20]. http://www.eol. cn/html/c/16dxsjybg/index. shtml.

[2] Chenguang Han and Shaowei Qu. Study on constructing evaluation index system with entrepreneurial capability of science and engineering college students [J]. Experimental technology and management, vol.7, pp.208 -210 +213,2016.

[3] Wu Ting. Zeng Yifan, Zeng Liji. Research on the evaluation of innovation and entrepreneurship of application-oriented college students based on AHP. Journal of Jiangxi youth vocational college, vol. 6, pp.21 -24,2015.

[4] Li Ziaofeng, Zhang Li and Xu Jiuping, The establishment of multidimensional extension-matterelement model for evaluation of college students' entrepreneurial competence and its application, Soft science, vol.10,pp.135-138,2013.

[5] Wang Liuying, Study of the Evaluation Index system for university students' entrepreneurial competence, Journal of Zhejiang youth college, vol. 4, pp. 35 -39, 2012. 